\title{
How Far, by Which Route, and Why? A Spatial Analysis of Pedestrian Preference
}

\author{
Asha Weinstein \\ (corresponding author) \\ Assistant Professor, Department of Urban and Regional Planning \\ San José State University \\ One Washington Square, San Jose, CA 95192-0185 \\ email: asha.weinstein@sjsu.edu \\ 408-924-5853; 408-924-5872 (fax) \\ Vanessa Bekkouche \\ Research Assistant, Public Policy and Management \\ University of Oregon \\ Katja Irvin \\ Research Assistant, Department of Urban and Regional Planning \\ San José State University \\ Marc Schlossberg \\ Assistant Professor, Planning, Public Policy and Management \\ University of Oregon
}

November 15, 2006

Word count: $4907+10$ tables $=7,407$ words

Submitted for presentation at the 2007 Annual Meeting of the Transportation Research Board This work was supported by the Mineta Transportation Institute at San José State University.

Weinstein and Schlossberg are both Research Associates of the Institute. 


\begin{abstract}
There is an increasing interest in community walkability, as reflected in the growing number of state and federal initiatives on Safe Routes to School, the new concern over a national obesity epidemic (especially in children), and a wide range of policy initiatives designed to convince travelers to switch from auto trips to more environmentally sustainable bicycle and walking trips. In each of these cases, policy makers recognize walking as a key mode of travel and believe that increasing the number of walk trips is a key goal.

Despite the seeming simplicity of the goal, we know very little about how far people actually walk or about how street design affects people's willingness or capacity to access their desired destinations by walking. This paper reports on a survey designed to answer two primary research questions related to the topic of pedestrian behavior: (1) How far do pedestrians walk to light rail stations? (2) What environmental factors do they say influence their route choice? The paper concludes with five major findings about our study population at five rail transit stations in the San Francisco Bay Area in California and in Portland, Oregon::
\end{abstract}

1. Pedestrians walk considerably farther to access light rail stations than commonly assumed.

2. Pedestrians believe that their primary consideration in choosing a route is minimizing time and distance.

3. Secondary factors influencing route choice are safety and, to a lesser extent, attractiveness of the route, sidewalk quality, and the absence of long waits at traffic lights.

4. Pedestrians vary considerably in how accurately they estimate the distance of a regular walk trip.

5. Asking survey respondents to trace their walking route on a local map is an effective research technique. 


\section{INTRODUCTION}

There is an increasing interest in community walkability, as reflected in the growing number of state and federal initiatives on Safe Routes to School, the new concern over a national obesity epidemic (especially in children), and a wide range of policy initiatives designed to convince travelers to switch from auto trips to more environmentally sustainable bicycle and walking trips. In each of these cases, policy makers recognize walking as a key mode of travel and believe that increasing the number of walk trips is a key goal.

Despite the seeming simplicity of the goal, we know very little about how far people actually walk or about how street design affects people's willingness or capacity to access their desired destinations by walking. Developing new tools to identify walk trip distances is a key research challenge, as is learning to characterize the local environment from a pedestrian point of view. This paper reports on a survey designed to answer two primary research questions related to the topic of pedestrian behavior:

1. How far do pedestrians walk to light rail stations?

2. What environmental factors do they say influence their route choice?

The next section of the paper sets the context for the research by examining related literature. A description of the survey methodology comes next, followed by an analysis of the survey findings, and then the paper's conclusions.

\section{LITERATURE REVIEW}

As explained in the introduction, the study addressed two primary questions:

1. How far do pedestrians walk to light rail stations?

2. What environmental factors influence their route choice?

For neither the question of how far pedestrians walk nor the factors that influence their route choice is there a well-established literature providing firm answers to the questions. While there are many rules of thumb and educated guesses, relatively little research exists on walking behavior in general, and these topics in particular. Until the mid-1990s, pedestrian behavior was virtually ignored in the transportation and planning literatures. In the last decade, and especially the last five years, the topic has suddenly become popular and many papers related to pedestrians have been published or underway. Much of the new literature has come from the public health community, complementing work done by planning and transportation researchers.

The earliest and largest body of research, which comes from the transportation planning community, assesses the factors that influence people to choose one mode of travel instead of another. In general, the authors of these studies want to understand how to shift Americans away from solo driving trips and towards transit, biking, or walking. Because the research was usually designed solely to discover why people choose to walk instead of drive, most studies did not examine the distances or routes walkers traveled. The majority of these studies claim to look at what is often called the "three Ds": density, diversity, and design, though in reality, the studies tend to focus on the first of the two Ds, density and diversity of land-uses. Many researchers have concluded that residents are more likely to walk in dense neighborhoods that include a diverse mix of nonresidential uses within a short distance $(1,2,3)$, though a subset of the 
research community remains unconvinced that the association is very strong, except for comparisons between extremely high and extremely low densities $(4,5)$.

Despite the rhetoric about the 3 Ds, micro-scale urban design and environmental factors were often ignored, likely because no pre-existing datasets captured design factors such as the presence of greenery, attractive buildings, smooth and wide sidewalks, traffic control devices that aid pedestrians crossing the street, or the presence of heavy traffic. In North America and Europe there were scattered studies on the topic from the 1970s through the mid-1990s, many focusing on how heavy traffic volumes discourage walkers $(6,7,8,9,10,11,12,13,14,15,16)$. Since 2000, there has been a burst of enthusiasm for taking on the design question more rigorously, with a number of studies on the topic appearing in the last decade $(17,18,19,20)$. However, researchers have quickly discovered that pedestrian behavior is highly complex and difficult to study, and the existing body of research points to few consistent findings. A recent review of the evidence linking physical activity with the built environment concluded that there is limited evidence showing a connection between neighborhood design and walking, but that further research is needed to determine if there is truly no link or if existing research has not been designed properly to reveal real relationships (21).

There is even less literature looking specifically at how far pedestrians walk than there is about what factors influence people to walk. The main sources of information are the U.S. Census, National Household Travel Survey, and regional household travel surveys. These surveys often report the number of walk trips made, but do not necessarily include trip distances, and even when they do, the data is often suspect (22). In the 2001 NHTS, for example, surveyors recoded many walk trip distances to the nearest mile. Given that most walk trips are quite short, this recording method makes the data almost useless for understanding walk trip distances with any precision.

In terms of how far pedestrians walk to access light rail specifically, most of the existing data is collected by transit agencies conducted internal surveys of their passengers. Researchers usually do not have easy access to the data, as there are not centralized databanks that collect the surveys. In addition, such surveys usually ask respondents to estimate the distance they walked, and thus the data may not be highly accurate. One study from the mid-1990s, however, gathered a few such surveys from the United States and Canada and conducted a survey of light-rail riders in Calgary, Canada. The authors found that the median walking distance in Calgary was about a fifth of a mile, though at suburban stations it was twice that distance (23).

\section{METHODOLOGY}

In the survey conducted for this research, respondents were asked a series of questions about how far and how long they walked to the station, what factors influenced their choice of route, their attitudes towards walking, and some basic demographic questions.

Surveys were distributed at five transit stations. Two were in the San Francisco Bay Area, in California: one in San Jose (Japantown) and one in El Cerrito (El Cerrito Plaza). The other three were in Portland, Oregon (Hollywood, Gresham, and Rockwood). The primary criteria for selecting the station areas was to find neighborhoods where pedestrians would have a reasonably high number of different route options. We assumed that people would not be willing to walk more than a little bit out of their way to find a nicer route, and so we selected only neighborhoods with streets laid out in a grid pattern. With a grid street pattern, respondents had multiple routes to choose from that were all approximately the same distance. We also chose 
neighborhoods where walkers would have a mix of local and collector or arterial streets, as well as both residential and mixed-use or commercial streets.

Surveys were distributed at transit stations to people who walked to the transit stop. Between one and three surveyors distributed surveys, depending on the day and station, and they worked between 6 a.m. and 10 a.m. on mostly weekday mornings, from February to May 2006. Each surveyor was instructed to approach all people waiting at the station and ask how they arrived at the station. The surveyors followed a script for consistency. Those people who responded that they walked to the station were asked follow-up questions to determine their eligibility for the study: (1) If they were over 18 years of age, and (2) If they would be willing to participate in the study anonymously. Willing survey respondents received a six-page written survey and a pen. They were told they could either return the completed survey to the surveyor at the station or mail it back in a pre-stamped envelope.

The survey included three sections:

1. Questions on walking behavior, preferences, and route choice.

2. A map inserted in the survey on which respondents were asked to trace their walking route. Respondents were also asked to mark intersections and streets they avoided on their walk if they had not indicated them in writing in the first part.

3. Questions on basic demographics of the respondents.

A total of 328 surveys were returned by respondents. Table 1 shows the number returned per station, as well as the response rate per station. Almost two-thirds of the surveys $(64 \%)$ came from the two Bay Area stations; over a third of the surveys came from El Cerrito Plaza station and just over another quarter came from the Japantown. Of the remaining surveys, almost a quarter came from Portland's Hollywood station (24\%), and the Gresham and Rockwood stations in Portland provided the remaining few surveys.

TABLE 1 Survey Response Rates, by Station

\begin{tabular}{lcc}
\hline Station & $\begin{array}{c}\text { \#/Completed, } \\
\text { Usable Surveys }\end{array}$ & $\begin{array}{c}\text { Response Rate } \\
\text { (\%) }\end{array}$ \\
\hline El Cerrito Plaza & 120 & 71 \\
Japantown & 90 & 49 \\
Hollywood & 78 & 45 \\
Gresham & 15 & 15 \\
Rockwood & 25 & 23 \\
TOTAL & 328 & 45 \\
\hline a Response rate is defined as the number of surveys returned as a proportion of \\
the number of surveys distributed. Some riders contacted were not given a \\
survey because they had not walked or refused to participate.
\end{tabular}

The response rate for the survey was quite high. For the total population, the response rate was $45 \%$. El Cerrito Plaza had the highest response rate, at $71 \%$, while response rates from the other stations ranged from $15 \%$ to $49 \%$. We calculated the response rate as the number of surveys returned as a proportion of the number of surveys distributed. Some transit riders 
approached by our surveyors were not given a survey to complete because they did not wish to participate or because they had not walked to the station.

Although some surveys had missing responses for a few individual questions, all of the surveys were complete enough to be included in the final data set. The number of responses contributing to the results varied slightly for each question, however.

\section{ANALYSIS OF SURVEY FINDINGS}

This section of the paper first describes the basic socio-demographic characteristics of the survey respondents, and then discusses the results of the survey. Sections discuss respondents' trip purposes, how many people stopped along their walk and what for, how far respondents said they walked as well as our own calculations of the distances they traveled, the factors that influenced their route choices, and their attitudes towards walking.

\section{Who were the survey respondents?}

Table 2 summarizes some socio-demographic statistics about the survey respondents. They were roughly half male and half female, about three-quarters self-identified as white, and threequarters were adults between the ages of 30 and 59. The median household income was $\$ 60,000$, and slightly over half the respondents said they rented their home. Almost one-third of the group rarely or never had access to a car, indicating that a fairly high proportion of the respondents were transit-dependent.

The groups of respondents from each station were all roughly similar to the total population of respondents, with just a few notable differences. The Bay Area respondents were a racially diverse group, while the Portland respondents were nearly all white. Also, the small sample of respondents from the Portland stations of Gresham and Rockwood had considerably lower household incomes and, correspondingly, were more likely to rent than own their homes. The Rockwood population was also highly transit dependent, with 67\% saying that they never or only occasionally had access to a car.

\section{Trips purposes and origins}

Most respondents made home-based trips to work (see Table 3). Among the full population, $81 \%$ made commute trips, another 5\% made trips to school, and $8 \%$ made personal shopping trips. This pattern held roughly consistent across all the stations, except that Japantown had fewer commute trips and considerably more shopping trips (21\%), whereas Gresham riders made fewer commute trips and more trips to school (33\%).

\section{Stops during the trips}

After reporting how far and for how long they walked, respondents were asked if they had stopped along the way. If they had, follow-up questions probed the reason for the stop and how long they stopped for. The vast majority, $87 \%$ did not stop (see Table 4 ). Of the $13 \%$ of respondents who did stop, about half stopped to buy food or a drink; the others stopped either to buy a newspaper, to talk to somebody, or for "other" reasons. The median time for these stops was just three minutes, consistent with stops made by people popping into a small business to make a quick purchase. The average stop times was longer, however, reflecting the fact that some people did stop for much longer time periods (up to 45 minutes for the longest stop). 
TABLE 2 Demographics of Survey Respondents ${ }^{\mathrm{a}}$

\begin{tabular}{|c|c|c|c|c|c|c|}
\hline & \multirow[b]{2}{*}{$\begin{array}{c}\text { All } \\
\text { Stations }\end{array}$} & \multicolumn{2}{|c|}{ Bay Area } & \multicolumn{3}{|c|}{ Portland } \\
\hline & & $\begin{array}{c}\text { EI } \\
\text { Cerrito }\end{array}$ & $\begin{array}{c}\text { Japan- } \\
\text { town }\end{array}$ & $\begin{array}{l}\text { Gres- } \\
\text { ham }\end{array}$ & $\begin{array}{l}\text { Holly- } \\
\text { wood }\end{array}$ & $\begin{array}{l}\text { Rock- } \\
\text { wood }\end{array}$ \\
\hline \multicolumn{7}{|l|}{ Gender } \\
\hline Male & $53 \%$ & $49 \%$ & $66 \%$ & $40 \%$ & $47 \%$ & $52 \%$ \\
\hline Female & $47 \%$ & $51 \%$ & $34 \%$ & $60 \%$ & $53 \%$ & $48 \%$ \\
\hline \multicolumn{7}{|l|}{ Race } \\
\hline White & $74 \%$ & $68 \%$ & $59 \%$ & $93 \%$ & $96 \%$ & $86 \%$ \\
\hline Black & $2 \%$ & $0 \%$ & $2 \%$ & $0 \%$ & $1 \%$ & $9 \%$ \\
\hline $\begin{array}{l}\text { Asian/Pacific } \\
\text { Islander }\end{array}$ & $15 \%$ & $23 \%$ & $20 \%$ & $0 \%$ & $1 \%$ & $5 \%$ \\
\hline Other & $5 \%$ & $4 \%$ & $11 \%$ & $0 \%$ & $0 \%$ & $0 \%$ \\
\hline Mixed race & $5 \%$ & $5 \%$ & $9 \%$ & $7 \%$ & $1 \%$ & $0 \%$ \\
\hline \multicolumn{7}{|l|}{ Age } \\
\hline $18-29$ & $19 \%$ & $15 \%$ & $25 \%$ & $23 \%$ & $15 \%$ & $29 \%$ \\
\hline $30-39$ & $30 \%$ & $34 \%$ & $26 \%$ & $15 \%$ & $32 \%$ & $29 \%$ \\
\hline $40-49$ & $23 \%$ & $20 \%$ & $26 \%$ & $39 \%$ & $25 \%$ & $13 \%$ \\
\hline $50-59$ & $20 \%$ & $25 \%$ & $12 \%$ & $8 \%$ & $23 \%$ & $25 \%$ \\
\hline $60+$ & $8 \%$ & $7 \%$ & $10 \%$ & $15 \%$ & $6 \%$ & $4 \%$ \\
\hline \multicolumn{7}{|l|}{ Household income } \\
\hline Median & $\$ 60,000$ & $\$ 80,000$ & $\$ 60,000$ & $\$ 35,000$ & $\$ 70,000$ & $\$ 20,000$ \\
\hline \multicolumn{7}{|l|}{ Own/rent home } \\
\hline Own & $44 \%$ & $45 \%$ & $38 \%$ & $29 \%$ & $60 \%$ & $21 \%$ \\
\hline Rent & $56 \%$ & $55 \%$ & $62 \%$ & $71 \%$ & $40 \%$ & $79 \%$ \\
\hline \multicolumn{7}{|l|}{ Driver's license? } \\
\hline Yes & $84 \%$ & $91 \%$ & $76 \%$ & $80 \%$ & $86 \%$ & $75 \%$ \\
\hline No & $16 \%$ & $9 \%$ & $24 \%$ & $20 \%$ & $14 \%$ & $25 \%$ \\
\hline \multicolumn{7}{|l|}{ Access to a car } \\
\hline Never/ occasionally & $30 \%$ & $16 \%$ & $36 \%$ & $33 \%$ & $32 \%$ & $67 \%$ \\
\hline $\begin{array}{l}\text { Most of the } \\
\text { time/always }\end{array}$ & $70 \%$ & $84 \%$ & $64 \%$ & $67 \%$ & $69 \%$ & $33 \%$ \\
\hline
\end{tabular}


TABLE 3 Trip Purposes and Origins ${ }^{\mathrm{a}}$

\begin{tabular}{|c|c|c|c|c|c|c|}
\hline \multirow[b]{2}{*}{ Trip purpose } & \multirow{2}{*}{$\begin{array}{c}\text { All } \\
\text { Stations }\end{array}$} & \multicolumn{2}{|c|}{ Bay Area } & \multicolumn{3}{|c|}{ Portland } \\
\hline & & EI Cerrito & Japantown & Hollywood & Rockwood & Gresham \\
\hline Work & $81 \%$ & $87 \%$ & $68 \%$ & $86 \%$ & $84 \%$ & $67 \%$ \\
\hline School & 5 & 4 & 2 & 4 & 4 & 33 \\
\hline Personal shopping & 8 & 3 & 21 & 6 & 4 & 0 \\
\hline Other & 6 & 6 & 8 & 4 & 8 & 0 \\
\hline \multicolumn{7}{|l|}{ Origin } \\
\hline Home & 96 & 99 & 92 & 95 & 100 & 100 \\
\hline Work & 1 & 1 & 1 & 1 & 0 & 0 \\
\hline Other & 3 & 0 & 7 & 4 & 0 & 0 \\
\hline
\end{tabular}

${ }^{\mathrm{a}}$ Percentages may not sum to $100 \%$ due to rounding.

TABLE 4 How Many People Stopped, For What Reason, and How Long ${ }^{a}$

\begin{tabular}{|c|c|c|c|c|c|c|}
\hline & \multirow[b]{2}{*}{ Combined } & \multicolumn{2}{|c|}{ Bay Area } & \multicolumn{3}{|c|}{ Portland } \\
\hline & & $\begin{array}{c}\text { El } \\
\text { Cerrito }\end{array}$ & $\begin{array}{l}\text { Japan- } \\
\text { town }\end{array}$ & $\begin{array}{l}\text { Holly- } \\
\text { wood }\end{array}$ & $\begin{array}{l}\text { Rock- } \\
\text { wood }\end{array}$ & Gresham \\
\hline $\begin{array}{l}\% \text { stopping for any } \\
\text { reason }\end{array}$ & $13 \%$ & $10 \%$ & $12 \%$ & $14 \%$ & $32 \%$ & $0 \%$ \\
\hline \multicolumn{7}{|l|}{ \% stopping for: } \\
\hline Food & $7 \%$ & $10 \%$ & $4 \%$ & $9 \%$ & $28 \%$ & $0 \%$ \\
\hline Newspaper & $2 \%$ & $4 \%$ & $2 \%$ & $0 \%$ & $4 \%$ & $0 \%$ \\
\hline To talk & $2 \%$ & $8 \%$ & $6 \%$ & $0 \%$ & $0 \%$ & $0 \%$ \\
\hline Other & $4 \%$ & $2 \%$ & $3 \%$ & $8 \%$ & $0 \%$ & $0 \%$ \\
\hline \multicolumn{7}{|l|}{ Time stopped } \\
\hline Mean & $6 \mathrm{~min}$. & $6 \mathrm{~min}$. & $5 \mathrm{~min}$. & $7 \mathrm{~min}$ & $7 \mathrm{~min}$ & $\mathrm{n} / \mathrm{a}$ \\
\hline Median & $3 \mathrm{~min}$. & $3 \mathrm{~min}$. & $2 \mathrm{~min}$. & $3 \mathrm{~min}$. & $6 \mathrm{~min}$. & $\mathrm{n} / \mathrm{a}$ \\
\hline
\end{tabular}

${ }^{a}$ Percentages may not sum to $100 \%$ due to rounding.

\section{Trip distances}

\section{Self-reported distances}

Respondents were asked how far they had walked, in both miles and blocks. Almost all respondents entered the number of blocks ( $91 \%$ ), but only $64 \%$ entered the distance in miles. (The question was formatted on the page with a space to enter the distance in miles followed by a space to enter the number blocks on the same line. This particular layout on the page may have encouraged some people to think they could enter just one or the other.)

For the full group of respondents, the mean reported distance was 0.58 miles (see Table 5). Looking at how the data broke out in quartiles shows that a quarter of people reported walking just a quarter of a mile or less, the second quartile of people reported walking between a quarter mile and a half mile, the third quartile reported walking between half a mile and almost a 
full mile (0.95 miles), and the final quarter said they walked more than 0.95 miles. The responses clustered around $0.25,0.5$, and 1 mile, indicating the tendency of people to round off distances.

TABLE 5 Self-Reported Distance Walked in Miles, Blocks, and Minutes

\begin{tabular}{|c|c|c|c|c|c|c|}
\hline & \multirow{2}{*}{$\begin{array}{c}\text { All } \\
\text { stations }\end{array}$} & \multicolumn{2}{|c|}{ Bay Area } & \multicolumn{3}{|c|}{ Portland } \\
\hline & & El Cerrito & Japantown & Gresham & Hollywood & Rockwood \\
\hline \multicolumn{7}{|c|}{ Distance in miles } \\
\hline Mean & 0.58 & 0.65 & 0.45 & 0.43 & 0.62 & 0.49 \\
\hline $25^{\text {th }}$ percentile & 0.25 & 0.25 & 0.13 & 0.11 & 0.39 & 0.25 \\
\hline $50^{\text {th }}$ percentile & 0.50 & 0.50 & 0.28 & 0.30 & 0.50 & 0.50 \\
\hline $75^{\text {th }}$ percentile & 0.95 & 1.00 & 0.69 & 0.80 & 1.00 & 0.75 \\
\hline \multicolumn{7}{|c|}{ Distance in blocks } \\
\hline Mean & 6 & 6 & 4 & 4 & 8 & 5 \\
\hline $25^{\text {th }}$ percentile & 3 & 3 & 2 & 2 & 4 & 2 \\
\hline $50^{\text {th }}$ percentile & 5 & 5 & 4 & 2 & 6 & 3 \\
\hline $75^{\text {th }}$ percentile & 8 & 8 & 6 & 4 & 10 & 6 \\
\hline \multicolumn{7}{|l|}{ Time (minutes) } \\
\hline Mean & 10 & 11 & 8 & 7 & 11 & 10 \\
\hline 25th percentile & 5 & 6 & 5 & 3 & 5 & 5 \\
\hline $50^{\text {th }}$ percentile & 10 & 10 & 6 & 6 & 10 & 10 \\
\hline $75^{\text {th }}$ percentile & 12 & 15 & 10 & 10 & 13 & 13 \\
\hline
\end{tabular}

\section{Actual distances}

We asked respondents to trace on a map the route they walked. For the El Cerrito, Japantown, and Hollywood stations, these routes were entered into a GIS database and the information used to calculate the exact length of each trip. The mean trip distance was just over a half mile (see Table 6TABLE 6), with the shortest trip 0.02 miles and the longest 1.88 miles. Looking at the distance data broken into quartiles shows that a quarter of respondents walked a quarter mile or less, the next quartile walked between a quarter and half mile, the third quartile walked between a half and two-thirds of a mile, and the final quarter walked over two-thirds of a mile.

TABLE 6 Actual Distances Walked

\begin{tabular}{lc}
\hline & $\begin{array}{c}\text { Distance } \\
\text { (miles) }\end{array}$ \\
\hline Mean & 0.52 \\
Minimum & 0.02 \\
Maximum & 1.88 \\
$25^{\text {th }}$ percentile & 0.27 \\
$50^{\text {th }}$ percentile & 0.47 \\
$75^{\text {th }}$ percentile & 0.68 \\
\hline
\end{tabular}


The accuracy of self-reported distances

We were interested to learn how accurately respondents estimated the distances they had walked. Many travel surveys ask respondents to estimate the distances they walk, but little is known about how accurate these estimates are. Close to half of the respondents (43\%) guessed quite accurately, within a tenth of a mile (see Table 7). However, other guesses were highly inaccurate, ranging from up to 1.07 miles over to 0.88 miles under the correct distance. The average guess was off by about 0.2 miles Each guess was off by $45 \%$ of the distance, on average, with $25 \%$ of respondents guessing within $11 \%$ and half guessing within $30 \%$ of the correct distance in miles. (Since the distances walked were short, the actual error in miles was trivial for most respondents.) On the other hand, 25\% of respondents' guesses were off by more than $50 \%$, a surprisingly large error, and $10 \%$ were off by more than $90 \%$.

TABLE 7 Accuracy of Self-Reported Trip Distances

\begin{tabular}{lcc}
\hline Accuracy of Distance Estimate & Percent & $\begin{array}{c}\text { Cumulative } \\
\text { Percent }\end{array}$ \\
\hline Within .1 mile & 43 & 43 \\
Off by 0.1 to 0.25 mile & 31 & 72 \\
Off by 0.25 to 0.5 mile & 20 & 94 \\
Off by $>0.5$ mile & 6 & 100 \\
\hline
\end{tabular}

\section{Factors influencing route choices}

After the survey respondents traced the route they walked on a map, the survey asked them to identify the factors that led them to choose a particular route they took. The survey addressed this issue in three steps. First, respondents were asked the open-ended question, "What are the main reasons why you chose your route today?" and given space to write three answers in their own words. On the next page, respondents were asked to rank the importance of 11 potential factors that might have influenced their route choice. The instructions read, "Below is a list of factors that other researchers have found to influence the routes people walk along. For each one, please mark how important it is to you." Finally, a last open-ended question asked, "Are there any other factors, positive or negative, that influenced your choice of route today?" Relatively few people answered this final question, so only the results of the first two questions are discussed below.

The first question, the open ended one, showed that by far the most important factor was choosing the shortest or fastest route. As shown in Table 8, 52\% of respondents mentioned this as the first item in their list, and almost two-thirds mentioned this somewhere among their three responses. An additional 9\% of respondents mentioned "convenience" as an important factor, and it may well be that convenience was their way of expressing the same concept - choosing the quickest route. The second most common set of responses had to do with safety, mentioned by $28 \%$ of respondents. Most of these related in some way to safety from traffic (people mentioned issues like low traffic volumes or an intersection where it was easy to cross a large street), although a few people mentioned crime safety issues. Although safety was a popular response, only $8 \%$ of people mentioned it as their first item on the list; safety was somewhat 
more common as the second item, appearing here $14 \%$ of the time. Finally, very small numbers of respondents mentioned choosing their routes based either on the attractiveness of the route (e.g., nice landscaping or attractive buildings) or because they wanted to stop at a particular business.

\section{TABLE 8 Percent of People Volunteering a Factor as Influencing Their Route Choice}

\begin{tabular}{lcccc} 
Question: What are the main reasons why you chose your route today? & \\
\hline Factor Type & $\begin{array}{c}\text { Anywhere } \\
\text { in List }\end{array}$ & First & Second & Third \\
\hline Shortest/fastest & $64 \%$ & $52 \%$ & $10 \%$ & $3 \%$ \\
Safety & 28 & 8 & 14 & 6 \\
Convenience & 9 & 6 & 2 & 1 \\
Attractive & 8 & 2 & 3 & 2 \\
Habit & 6 & 3 & 1 & 2 \\
Stopped at a business & 3 & 2 & 2 & 0 \\
& & & & \\
Other & 27 & 13 & 9 & 5 \\
Nonsense & 16 & 9 & 5 & 3 \\
Left blank & N/A & 3 & 50 & 77 \\
\hline
\end{tabular}

${ }^{\text {a }}$ Percentages may not sum to $100 \%$ due to rounding.

These priorities were partially validated in the next question, which asked respondents to rate the importance of 11 different factors. As shown in Table 9, 99\% of respondents rated choosing the shortest route as either very important or somewhat important, with the bulk of those saying it was very important ( $82 \%$ of respondents). This finding confirms the results of the open-ended question, where responses related to distance predominated. On the other hand, safety considerations showed up as considerably more important in the second question than they did in the previous, open-ended question. About half of respondents rated as "very important" having traffic devices present and having traffic drive at safe speeds; those numbers jumped considerably to $85 \%$ and $87 \%$ when one combines the responses of those who responded that these factors were either very or somewhat important. Other factors that were rated as very or somewhat important by at least $50 \%$ of respondents were having sidewalks in good condition; the presence of attractive buildings, trees, and landscaping; having no traffic lights where it took a long time to cross; the presence of other people out walking; and having shops or businesses to stop in. Only the first two of these were rated as "very important" by at least a third of respondents, however. Finally, three factors rated as important by relatively few people were having shops or businesses with windows to look at; having benches or other places to sit; and having a friend or neighbor along the route. 


\section{TABLE 9 How Respondents Rated the Importance of Factors that Might Influence Their Route Choice ${ }^{\text {a }}$}

Question: Below is a list of factors that other researchers have found to influence the routes people walk along. For each one, please mark how important it is to you.

\begin{tabular}{lccc}
\hline Factor $^{\mathbf{b}}$ & $\begin{array}{c}\text { Very } \\
\text { Important }\end{array}$ & $\begin{array}{c}\text { Somewhat } \\
\text { Important }\end{array}$ & $\begin{array}{c}\text { Not } \\
\text { Important }\end{array}$ \\
\hline Shortest route & $82 \%$ & $17 \%$ & $1 \%$ \\
Traffic devices are present & 55 & 30 & 15 \\
Traffic drives at safe speeds & 46 & 41 & 13 \\
Sidewalks in good condition & 43 & 44 & 13 \\
Presence of attractive buildings, trees, and landscaping & 35 & 44 & 21 \\
No traffic lights where it takes a long time to cross & 29 & 39 & 32 \\
Other people out walking & 23 & 37 & 40 \\
Shops/businesses to stop in & 14 & 32 & 54 \\
Shops/businesses with window to look in & 11 & 25 & 65 \\
Benches/places to sit & 11 & 15 & 75 \\
Friend/neighbor along the route & 7 & 18 & 75 \\
\hline
\end{tabular}

a Percentages may not sum to $100 \%$ due to rounding.

${ }^{b}$ Note: Factors were ordered differently in the survey itself.

\section{Attitudes towards walking}

Towards the end of the survey, respondents were asked how strongly they agreed with a series of statements describing different reasons that they might choose to walk. Overall, respondents had very positive attitudes towards walking, perhaps explaining the high level of willingness to complete and return our survey. The first two questions asked if people liked walking and if they found walking relaxing, and in both cases $97 \%$ either strongly agreed or agreed with the statement (see Table 10). Another question asked if respondents walked in order to get exercise or health benefits, and again virtually all agreed or strongly agreed (94\%). Slightly lower percentages of people agreed that they sometimes walk because it is the convenient mode of travel $(89 \%)$ or because it is the cheapest way to travel $(80 \%)$.

\section{TABLE 10 Attitudes Towards Walking ${ }^{a}$}

Question: For each statement below, please mark how strongly you agree or disagree with it.

\begin{tabular}{lccc}
\hline Statement & $\begin{array}{c}\text { Strongly } \\
\text { Agree }\end{array}$ & $\begin{array}{c}\text { Agree } \\
\text { I like walking }\end{array}$ & $\begin{array}{c}\text { Disagree or } \\
\text { Strongly } \\
\text { Disagree }\end{array}$ \\
$\begin{array}{l}\text { Walking is relaxing } \\
\text { I walk to get exercise or other health benefits }\end{array}$ & 70 & $19 \%$ & $3 \%$ \\
I sometimes walk because it is the fastest and/or most & 51 & 27 & 3 \\
$\begin{array}{l}\text { convenient way to get somewhere } \\
\text { I sometimes walk because it is the cheapest way to get } \\
\text { around }\end{array}$ & 46 & 34 & 6 \\
\hline
\end{tabular}

${ }^{\text {a }}$ Percentages may not sum to $100 \%$ due to rounding. 


\section{CONCLUSIONS}

This study surveyed pedestrians walking to five different light rail stations to determine how far they walked and the factors that they believed influenced their choice of route. Five primary conclusions about the survey population stand about among the findings, four related to pedestrian behavior and one related to the study methodology.

\section{Pedestrians walk considerably farther to access light rail stations than commonly assumed.}

Conventional wisdom among planners has often been that pedestrians in the U.S. will only walk a quarter to a third of a mile for any reason, including to access transit. A paper from the mid1990s looking at how far transit agencies and transportation modelers assume that pedestrians will walk to a light rail stations found very short distances, most well under a half mile (23). The results of our study suggest quite differently, at least for walk trips to access rail transit. The median trip distance was 0.47 miles, showing that fully half the people surveyed walked at least a half mile to access the train station. These results suggest that transportation and land-use planners designing transit-oriented developments should assume many train riders will walk considerably farther than they may have previously thought, at least for commute trips.

\section{Pedestrians believe that their primary consideration in choosing a route is minimizing time and distance.}

The survey explored the reasons that pedestrians choose particular routes in two ways, first asking about route choice factors as an open-ended question and then asking respondents to rate the importance of a list of factors that might have influenced them. In both cases, respondents overwhelmingly indicated that their first priority was to choose the most direct and/or quickest route. Since almost all of our respondents were making a morning commute trip, it is not surprising that time would be a strong consideration for them. Follow-up research should be conducted to assess whether or not this finding holds for other kinds of trips. These results suggest that land-use planners who want to increase walk trips should ensure that pedestrians have available fairly direct routes to their destinations.

\section{Secondary factors influencing route choice are safety and, to a lesser extent, attractiveness of the route, sidewalk quality, and the absence of long waits at traffic lights.}

In both the open-ended and closed-ended questions about route choice, the most highly rated factors after distance had to do with safety. In the open-ended question, safety factors were the only other issue listed by over a quarter of respondents. In the closed ended questions, about half of respondents rated it as "very important" to have traffic devices present and traffic driving at safe speeds. The next most-cited "very important" factor was having sidewalks in good condition (43\%). Aesthetic issues, in the sense of attractive landscaping or buildings, was rated as very important by $35 \%$ of respondents, but raised by only $8 \%$ of the respondents in the openended question. The only other issues rated as "very important" by at least a quarter of respondents were having other people present (which may be a safety-related concern), and the absence of traffic lights with a long wait. 
When interpreting these results, it is important to keep in mind the context in which the respondents answered. First, all were thinking about a commute trip in the morning; for other trip purposes, their responses might vary. In addition, audits of the neighborhoods around the five stations, which were conducted for this study, showed that the pedestrian environment was relatively safe from crime and traffic, and most of the residential streets were of at least average attractiveness in terms of the built environment. Had the survey been conducted in run-down neighborhoods, respondents might have placed higher priority on the visual quality and maintenance of the built environment.

Overall, the study results suggest that planners trying to encourage walking should focus on creating direct routes and conditions where pedestrians feel safe to cross the street. Aesthetic issues doubtless are important for other reasons, such as making walking more pleasant, creating a neighborhood sense of place, or encouraging recreational walking, but they appear to be less critical in people's decision of whether or not to walk to a light rail station.

\section{Pedestrians vary considerably in how accurately they estimate the distance of a regular walk trip.}

Many travel surveys ask respondents to self-report the distances they travel. To date, there has been little information on how accurate those self-reported estimates might be. This study found that, on average over all responses, the difference between actual and perceived distance is modest. At least half of all respondents guessed within 0.13 miles of their actual route length. However, $25 \%$ of respondents' guesses were off by more than $50 \%$, suggesting that a substantial minority do not have a precise idea of how far they walked. A few of the individual guesses were also substantially off in terms of distance, as well as percent: guesses ranged from up to 1.07 miles over to 0.88 miles under the correct distance.

These findings should be interpreted carefully when applying them to other surveys asking for self-reported walk trip distances. This survey asked people to estimate the distance of a route they walk routinely, so they may well have a more accurate sense of distance than they would on a less familiar trip. It seems likely that other surveys asking people to report the distances for routine trips might have similar (in)accuracies, but the study results should not be assumed to hold true for other types of trip that surveyors ask about. In addition, it may be that people making significantly longer trips would estimate distances less accurately than did our respondents, who were walking relatively short distances.

\section{Asking survey respondents to trace their walking route on a local map is an effective research technique.}

Asking respondents to draw their route on a map is a relatively untested survey technique. We were unsure whether respondents would be willing to provide this information, or if they would fill out the map correctly so that the data would be useful. The results of this research show that it is highly effective. Of the 328 surveys received, the map was filled out correctly $93 \%$ of the time, generating 261 routes that could be analyzed for actual distance and other route characteristics. The route tracings were legible and precise enough that the research team had no trouble transferring the exact routes into a GIS database where the distance could be automatically calculated. In addition, the relatively high response rate for the survey (45\%) shows that the presence of the map did not discourage people from completing the survey. 


\section{ACKNOWLEDGMENTS}

This work was supported by the Mineta Transportation Institute at San José State University. The contents of the paper reflect the views of the authors, who are responsible for the facts and accuracy of the data presented. 


\section{REFERENCES}

1. Cervero, R. and K. Kockelman. Travel demand and the 3Ds: Density, diversity, and design. Transportation Research D, Vol. 2, No. 3, 1997, pp. 199-219.

2. Greenwald, M.J., and M.G. Boarnet. The Built Environment as a Determinant of Walking Behavior: Analyzing Non-Work Pedestrian Travel in Portland, Oregon. Center for Activity Systems Analysis, University of California at Irvine (Paper UCI-ITS-AS-WP-01-4), 2001.

3. Cervero, R. and R. Gorham, Commuting in transit versus automobile neighborhoods. Journal of the American Planning Association, Vol. 61, 1995, No. 2, pp. 199-219.

4. Badoe, D.A., and E.J. Miller. Transportation-Land-Use Interaction: Empirical Findings in North America, and their Implications for Modeling. Transportation Research Part D, Vol. 5 No. 4, 2000, pp. 235-263.

5.. Crane, R. The Influence of Urban Form on Travel: An Interpretive Review. Journal of Planning Literature, Vol. 15, No. 1, 2000, pp. 3-23.

6.. Carp, F.M. "Walking as a Means of Transportation for Retired People." Gerontologist, Vol. 2, No. 2, 1971, pp. 104-111.

7. Lövemark, O. New Approaches to Pedestrian Problems. Journal of Transport Economics and Policy, Vol. 6, No. 1, 1972, pp. 3-9.

8. Neilson, Gordon K., and William K. Fowler. "Relation Between Transit Ridership and Walking Distances in a Low-Density Florida Retirement Area." Highway Research Record, No. 403, 1972, pp. 26-34.

9. City Engineering Department, Vancouver, B.C. Downtown Pedestrian Surveys. May 1978.

10. Mitchell, C.G.B. and R.G.F. Stokes. Walking as a Mode of Transport. TRRL Laboratory Report 1064, 1982.

11. May, A.D., I.G. Turvey, and P.G. Hopkinson. Studies of Pedestrian Amenity. Working Paper 204. Institute for Transport Studies, University of Leeds, April 1985.

12. Seneviratne, P. and P. Fraser. Issues Related to Planning for Pedestrian Needs in Central Business Districts. Transportation Research Record, No. 1141, 1987, pp. 7-14.

13. Hopkinson, P.G., A.D. May, and I.G. Turney. "The Influence of Town Center Conditions on Pedestrian Trip Behavior: Results from a Household Survey in Two Locations." Working Paper 246, Institute for Transport Studies, University of Leeds, December 1987.

14. Hoxie, R.E., et al. The Older Pedestrian. Journal of the American Geriatrics Society, Vol. 42, No. 4, 1994, pp. 444 - 450.

15. Handy, S. Urban Form and Pedestrian Choices: Study of Austin Neighborhoods. In Transportation Research Record, No. 1552, 1996, pp.135-144.

16. Shriver, K. Influence of environmental design on pedestrian travel behavior in four Austin neighborhoods. Transportation Research Record, No. 1587, 1997, pp. 64-75. 
17. Rodríguez, D.A., and J. Joo. The Relationship Between Non-Motorized Mode Choice and the Local Physical Environment. Transportation Research D, Vol. 9, No. 2, 2004, pp.151173.

18. Ewing, R, O. Clement, S. Handy, R.C. Brownson, and E. Winston. Identifying and Measuring Urban Design Qualities Related to Walkability (Final Report prepared for the Active Living Research Program of the Robert Wood Johnson Foundation). July 2005.

19. Kirtland, K. A. et al. Environmental measures of physical activity supports: Perception versus reality. American Journal of Preventive Medicine, Vol. 24, No. 4, 2003, pp. 323-331.

20. Pikora, T. J. et al. Developing a reliable audit instrument to measure the physical environment for physical activity. American Journal of Preventive Medicine, Vol. 23, No. 3, 2002, pp. 187-194.

21. Committee on Physical Activity, Transportation Research Board. Health, transportation and land use, does the built environment influence physical activity? Examining the evidence. Transportation Research Board Special Report 282, 2005.

22. Weinstein, A. and P. Schimek. How Much Do Americans Walk? An Analysis of the 2001 NHTS. Presented at the 2005 Annual Meeting of the Transportation Research Board.

23. O'Sullivan, S. and J. Morrall. Walking Distances To and From Light-Rail Transit Stations. Transportation Research Record, No. 1538, 1996, pp. 19-26. 